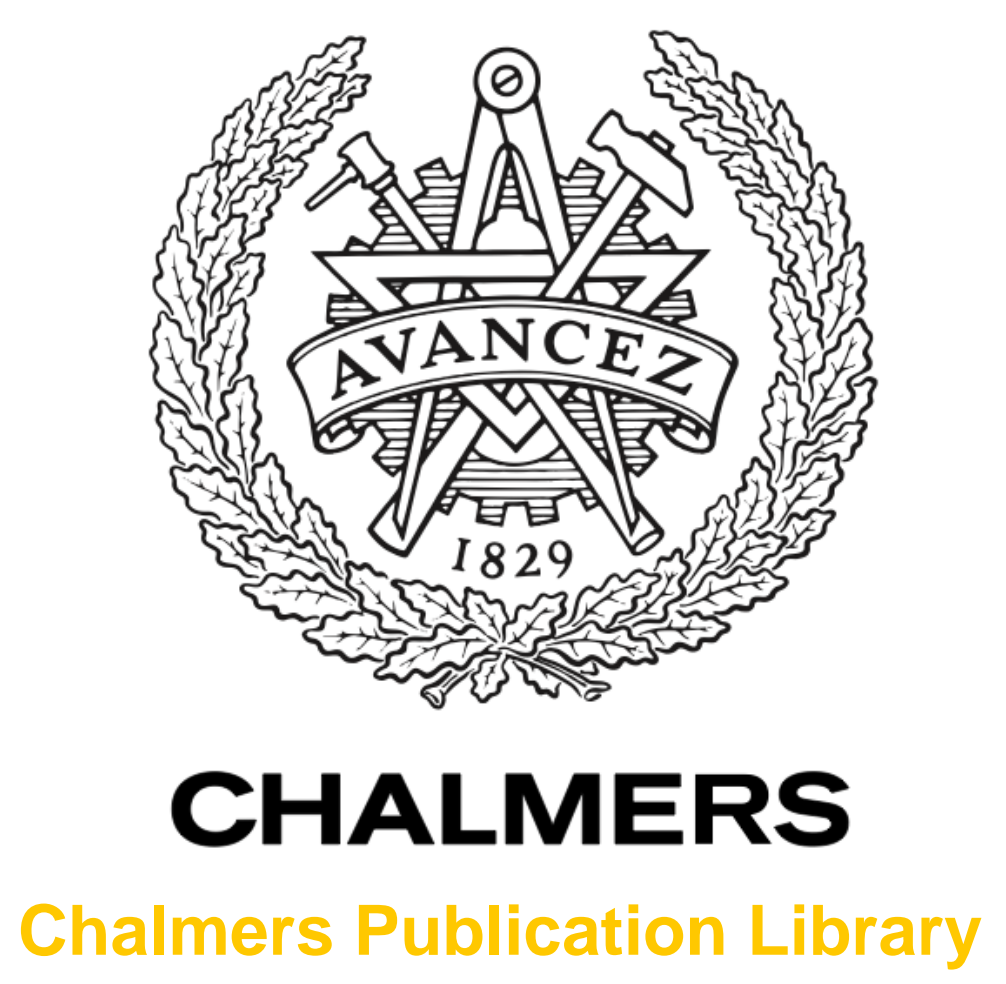

\title{
Structural behavior of corroded reinforced concrete structures
}

This document has been downloaded from Chalmers Publication Library (CPL). It is the author's version of a work that was accepted for publication in:

\section{The Fourth International Conference on Bridge Maintenance, Safety, Management, Health Monitoring and Informatics}

Citation for the published paper:

Zandi Hanjari, K. ; Lundgren, K. ; Kettil, P. et al. (2008) "Structural behavior of corroded reinforced concrete structures". The Fourth International Conference on Bridge Maintenance, Safety, Management, Health Monitoring and Informatics pp. 481.

Downloaded from: http://publications.lib.chalmers.se/publication/74066

Notice: Changes introduced as a result of publishing processes such as copy-editing and formatting may not be reflected in this document. For a definitive version of this work, please refer to the published source. Please note that access to the published version might require a subscription. 


\title{
Structural behavior of corroded reinforced concrete structures
}

\author{
K. Zandi Hanjari \& K. Lundgren \\ Department of Civil and Environmental Engineering, Chalmers University of Technology, Gothenburg, \\ Sweden \\ P. Kettil \\ Department of Applied Mechanics, Chalmers University of Technology, Gothenburg, Sweden \\ M. Plos \\ Department of Civil and Environmental Engineering, Chalmers University of Technology, Gothenburg, \\ Sweden
}

\begin{abstract}
This paper presents a methodology to analyze the mechanical behavior and remaining load-carrying capacity of corroded reinforced concrete structures. The effect of corrosion is modeled as a change in geometry and properties, i.e. reduction of steel area, removal of spalled concrete and modification of bond-slip properties. The methodology is tested on concrete beams affected by corrosion using finite element analysis and the results were compared with experiments.
\end{abstract}

\section{INTRODUCTION}

There is a growing need for reliable methods to predict the load-carrying capacity and remaining service life of deteriorated reinforced concrete structures as a decision basis for optimized maintenance and repair strategies, Rodriguez et al. (1997), Huang and Yang (1997). In an ongoing research project, load-carrying capacity of deteriorated reinforced concrete structures is studied on the component level. The part of the project presented here is focused on deterioration (damage) due to the corrosion of reinforcement.

The corrosion process transforms steel into rust, leading to (a) area reduction of the reinforcement bars and (b) volume expansion that generates splitting stresses in the concrete, which may crack and spall the concrete cover and affect the bond-slip between reinforcement and concrete. This has been studied by many researchers; for a state-of-the-art report see fib (2000).

While previous research has been mainly concerned with corrosion around a single reinforcement bar, see e.g. Almusallam et al. (1996) and Lundgren (2003), relatively little research has been concentrated to the practically important problem of assessing the residual loadcarrying capacity of corroded concrete structures. The aim of this research is to develop a methodology to quantify the load-carrying capacity of corroded reinforced concrete structures.

This paper presents a methodology to analyze the mechanical behavior and remaining loadcarrying capacity of corroded reinforced concrete structures. The effect of corrosion is modeled as a change in geometry and properties, i.e. reduction of steel area, removal of spalled concrete and modification of bond-slip properties. The modification of bond-slip properties is based on previous research where a detailed 3D solid finite element model has been developed and used to determine the 1D bond-slip response for corroded reinforcement, Lundgren (2003), Lundgren (2004), Schlune (2006), Lundgren et al. (in progress).

\section{METHODOLOGY - MODELING OF CORROSION DAMAGE}

In the following, a methodology to analyze the mechanical behavior of corroded reinforced concrete structures is proposed. It is assumed that the effect of corrosion can be modeled as a change in geometry and properties of the analysis model:

- Change of concrete geometry (removal of spalled concrete) 
- Change of steel area (reduction of bar diameter due to the corrosion penetration)

- Modification of bond-slip properties

The methodology is intended to be general in the sense that it can be used for different approximation levels, e.g. full non-linear analyses with 3D solid models, intermediate analyses with shell and frame models, to the simplest hand-calculations using beam models.

\subsection{Change of concrete geometry}

The corrosion process may crack and spall the concrete cover, which must be taken into account. The extent and depth of the spalled areas should be measured and documented. The geometry of analysis model should then be modified accordingly.

\subsection{Change of steel area}

The reduction of the effective steel area, or rebar diameter, is the most evident effect to take into account, see Equation 1.

$$
\phi=\phi_{0}-2 x
$$

where $\phi$ is the remaining effective diameter of the rebar, $\phi_{0}$ is the original diameter, and $x$ is the corrosion (rust) penetration. The reduction of rebar diameter is most accurately obtained by direct measurements. On a corroded structure, parts of the concrete cover have usually spalled off, and the remaining bar diameter could be measured on the exposed bars after removal of the rust layer. For less corroded structures where the cover has not yet spalled off, small parts of the cover could be removed at non-critical locations, and afterwards repaired. An alternative to direct measurement is to calculate an estimate of the corrosion penetration based on corrosion rate and time of corrosion initiation Meria et al. (2007).

\subsection{Change of bond-slip properties}

The corrosion process affects the bond-slip between reinforcement and concrete. This could lead to a brittle collapse of the structure, and hence the change in the bond-slip curve must be accounted for.

Areas with spalled off concrete covers and the corrosion penetration of corroded bars should be measured and documented in accordance with sections 2.1 and 2.2 above. In addition, crack patterns that indicate splitting of the cover should be measured and documented. The bond-slip properties of the analysis model should then be modified accordingly. The modification could be based on the following proposed method, based on the research presented in Lundgren (2003), Lundgren (2004), Schlune (2006), Lundgren et al. (in progress) and the 1D bond-slip model of CEB (1993).

In locations where the concrete cover has totally spalled off, the bond strength should be set to zero. In other areas where the cover still remains (but may be cracked), the bond-slip properties could be based on the following:

1. The bond strength $\tau_{b}$ versus slip $s$ curves and parameters of CEB (1993) are adopted for the uncorroded case. To account for intermediate cases in between the extreme cases "confined" (i.e. ductile pull-out failure) and "unconfined" (i.e. brittle failure due to cover cracking), the following interpolation formula is proposed Lundgren et al. (in progress):

$$
\tau_{b}=k \cdot \tau_{b, \text { conf }}+(1-k) \cdot \tau_{b, \text { unconf }}, \quad k=\max \left\{\begin{array}{l}
k_{c / d} \\
k_{\text {Asw }}
\end{array}\right.
$$

Where $k_{c / d}$ is a factor dependent on the cover to bar diameter ratio $c / d$ and $k_{\text {Asw }}$ is a factor that depends on the amount of effective transverse reinforcement $\mathrm{A}_{\mathrm{sw}} / \mathrm{s}$, according to Figure 1. 

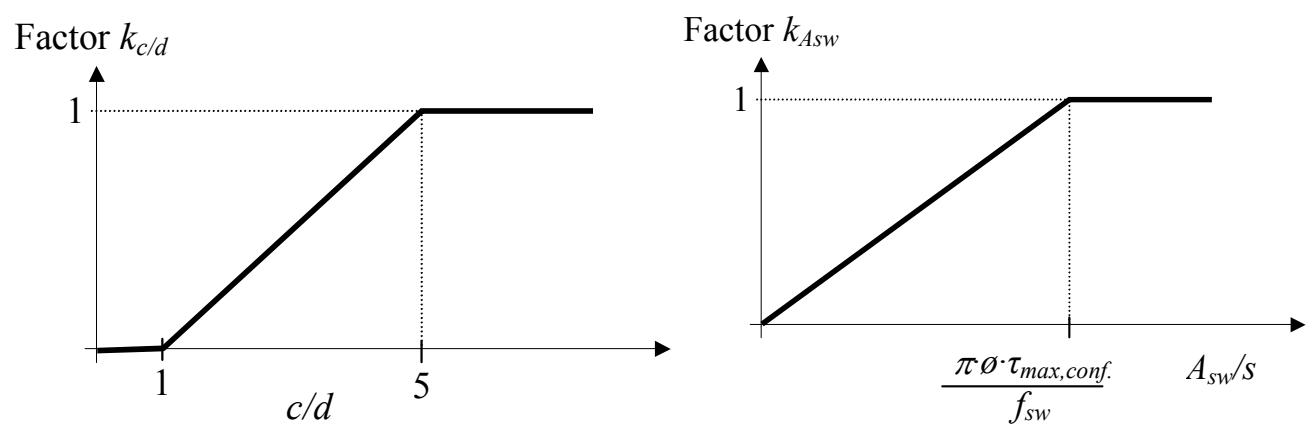

Figure 1. Interpolation factors

2. The effect of corrosion is taken into account by adjusting the CEB (1993) bond-slip curves as follows:

a. The bond-slip curve of the corroded bar is obtained by shifting (moving) the curve for the uncorrodded bar to the left by the distance

$$
\Delta s=a x
$$

where $a$ is assumed to be a constant and $x$ is the corrosion penetration. This was suggested by Schlune Schlune (2006), see also Lundgren et al. (2007), where the constant $a$ was found to be around 8.1 for the analyzed cases.

b. To account for the possible change in failure mode due to corrosion from pull-out to splitting failure, the parameters for the bond-slip curve for the corroded case is obtained by interpolation of the parameters of the uncorroded case. Every model parameter is interpolated, for example

$$
\tau_{\text {max }}=k_{f \text { mod }} \cdot \tau_{\text {max }, \text { conf }}+\left(1-k_{f \text { mod }}\right) \cdot \tau_{\text {max }, \text { unconf }}
$$

The factor $k_{f m o d}$, see Figure 2, depends on the ratio $x / x_{c r}$, where $x$ is the corrosion penetration and $x_{c r}$ is the corrosion level that cracks the cover. The corrosion penetration that causes cover cracking has been found by curve fitting to analysis results from the detailed 3D model, see Lundgren (2003), as given by the following formula

$$
x_{c r}=11 \cdot\left(\frac{f_{c c}}{40}\right)^{0.8} \cdot\left(\frac{c}{d}\right)^{1.5} \cdot\left(\frac{d}{16}\right)^{0.5}
$$

where $x_{c r}$ is the corrosion level that cracks the cover in $\mu \mathrm{m}, f_{c c}$ is the concrete compressive strength in $\mathrm{MPa}, c$ is the concrete cover in $\mathrm{mm}$, and $d$ is the reinforcement bar diameter in mm. In regions where cover cracking has been observed on the structure, the ratio $x / x_{c r}$ should be set to one.

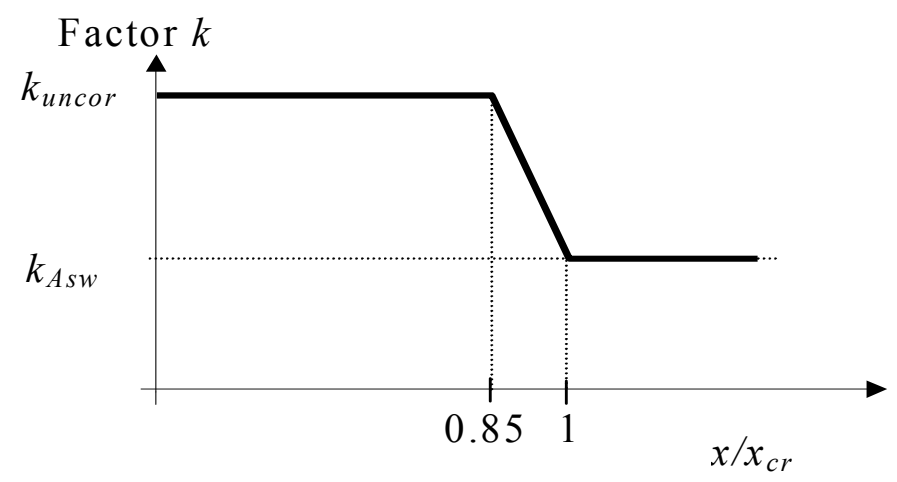

Figure 2. Factor to take a change of failure mode into account for corroded reinforcement 
This procedure can be applied to solid and structural analysis models where the bond-slip between the concrete and reinforcement is modeled by 1D bond-slip interface elements, such as in the analyses in Chapter 5. For simpler structural analysis models where the bond-slip is not directly accounted for in the model, it is proposed that the above procedure can be applied to calculation of required anchorage lengths Lundgren et al. (in progress) and subsequent checking of the curtailment and laps of the corroded reinforcement.

\section{EXPERIMENTAL SETUP FOR COMPARISON WITH FE ANALYSIS}

\subsection{Beam tests by Coronelli}

Coronelli (1998) has tested bond-slip behavior of uncorroded and corroded reinforcement using a four-point bending test on a beam with a hinge arrangement in the middle, see Figure 3, to give a well defined force in the reinforcement bar. In addition, the bar was only bonded to the concrete over a short length, to get a rather uniform bond stress. During the tests, the load, the mid deflection of the beam and slip at the passive ends of the rebar were measured, see Figure 3. Tests results were reported for $0 \%, 1.2 \%, 2.4 \%$ and $4.8 \%$ volume corrosion, corresponding to 0 , 50,100 and $150 \mu \mathrm{m}$ corrosion penetration on the tested Ø14 bar. For full details of tests see reference Coronelli (1998).

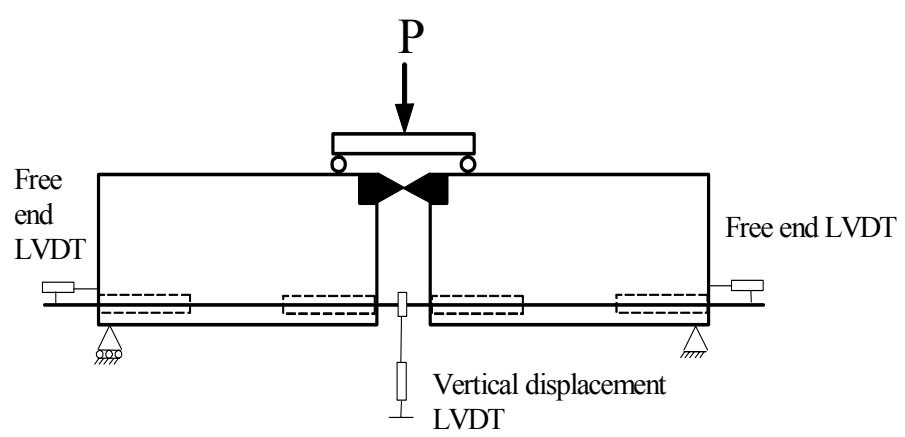

Figure 3. Beam tested by Coronelli

\subsection{Beam tests by Rodriguez et al.}

Rodriguez et al. (1997) tested the influence of reinforcement corrosion on reinforced concrete beams loaded in four-point bending. During the tests, the load and the mid deflection of the beam were measured. Test results were reported for different beam dimensions and reinforcement arrangements to produce different failure modes, and always for one uncorroded case and one corroded case. The beams modeled here were affected by 490, 540 and $490 \mu \mathrm{m}$ corrosion penetration of the tensile reinforcement, compressive reinforcement and stirrups, respectively.

\section{FINITE ELEMENT ANALYSIS}

\subsection{Beam tests by Coronelli}

The beam tests by Coronelli (1998), see brief description in section 3.1 above, were modeled and analyzed by the finite element method (FEM). The effect of reinforcement corrosion was modeled as a change of rebar diameter and by modification of bond-slip properties according to sections 2.2 and 2.3 above.

The beam was modeled in 2D, and due to symmetry; only half of the beam was modeled. The dimensions, reinforcement, boundary conditions and loading arrangement are shown in Figure 4. In the tests, steel plates and roller bearings have been used at the supports. In the FE-model, the steel plate was modeled as infinitely stiff by constraint equations, see left end of the beam in Figure 4. The FE nodes along the plate were tied to the centre node, thus forcing the nodes to remain in a straight line, but allowing for rotation. The center node was supported for displace- 
ment in the y-direction. Also for modeling of the loading plates on the top of the beam, the nodes were tied to remain in a straight line. At the symmetry line, see the right end of the beam in the Figure, the special hinge arrangement in the test was modeled by a steel plate with one node in the middle fixed in the $\mathrm{x}$-direction. Also the reinforcement bar node was fixed in the $\mathrm{x}$ direction.

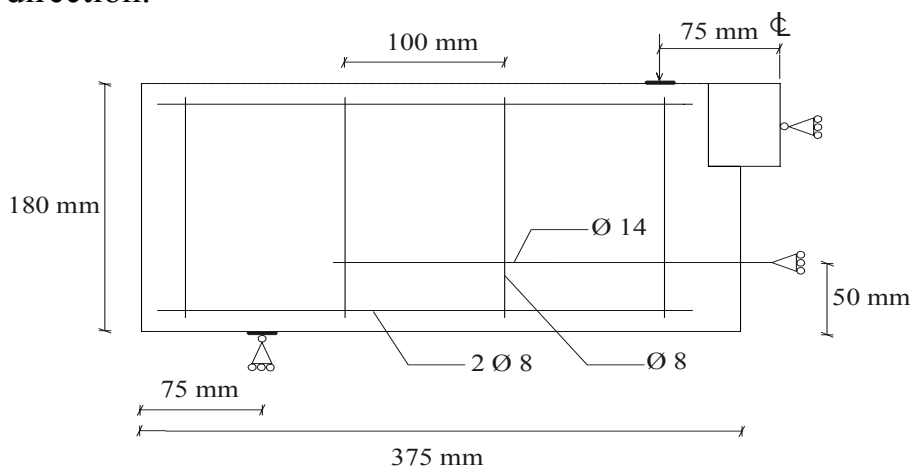

Figure 4. 2D model of beam test by Coronelli

For the concrete, 4-node quadrilateral plane stress solid elements were used. The concrete was modeled with a constitutive model based on non-linear fracture mechanics using a smeared rotating crack model based on total strain; see DIANA (2006). The crack band width was assumed to be equal to the element size. For the tension behavior of concrete, the curve by Hordijk et al. was chosen, as described in DIANA (2006), Hordijk (1991). For concrete in compression, a simple elastic ideal-plastic behavior was assumed. Material properties for the concrete and the reinforcement are described in Table 1.

Table 1 Material properties used in the analyses

\begin{tabular}{lllllll}
\hline \multicolumn{2}{l}{ Concrete } & & & & \multicolumn{2}{c}{ Reinforcement } \\
\cline { 1 - 2 } \cline { 5 - 7 } $\mathrm{f}_{\mathrm{cc}}$ & $\mathrm{f}_{\mathrm{ct}}$ & $\mathrm{G}_{\mathrm{F}}$ & $\mathrm{E}_{\mathrm{c}}$ & & $\mathrm{f}_{\mathrm{y}}$ & $\mathrm{E}_{\mathrm{c}}$ \\
{$[\mathrm{MPa}]$} & {$[\mathrm{MPa}]$} & {$[\mathrm{N} / \mathrm{m}]$} & {$[\mathrm{GPa}]$} & & {$[\mathrm{MPa}]$} & {$[\mathrm{GPa}]$} \\
36 & 2.77 & 73.5 & 31.37 & & 430 & 200 \\
\hline
\end{tabular}

The longitudinal reinforcement was modeled by 2-node truss elements. The effective diameter of the bar was adjusted with respect to the corrosion penetration according to section 2.2 above. Interaction between the reinforcement and the concrete was modeled with an interface element with a 1D bond-slip law as described in section 2.3 above. Figures 5 shows the resulting bond-slip curves for $150 \mu \mathrm{m}$ corrosion penetrations. The stirrups were embedded in the 4node quadrilateral plane stress solid elements, corresponding to perfect bond between the stirrups and the surrounding concrete.

An incremental static analysis was performed using a Newton-Raphsson iterative scheme to solve the non-linear equilibrium equations. In a phased analysis, first the self-weight load was applied. Then, the external load was gradually applied as prescribed displacement at the loading point.
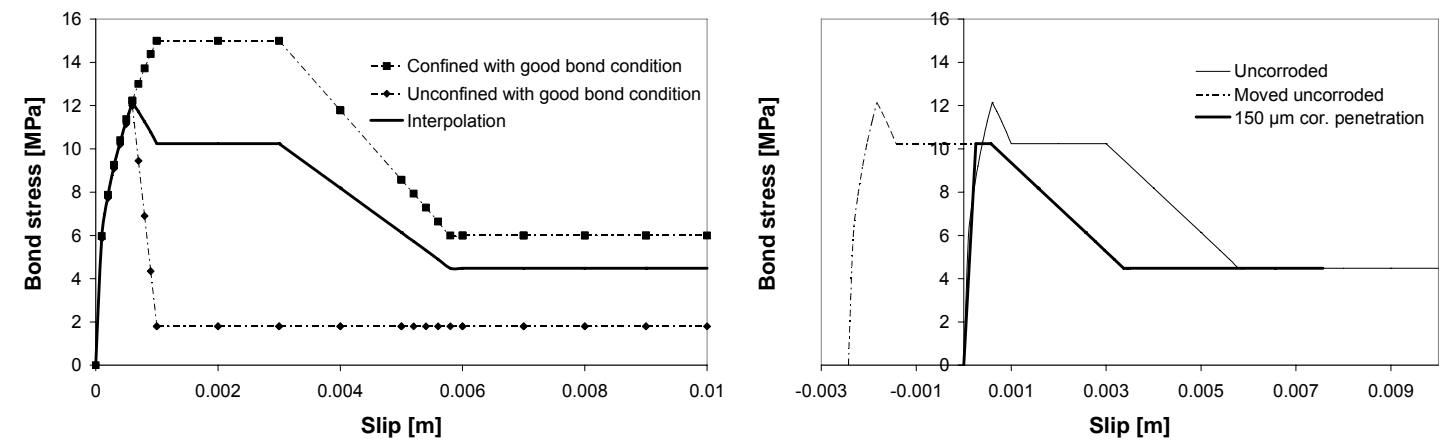

Figure 5. Bond-slip curve for uncorroded reinforcement obtained by interpolation of "confined" and "unconfined" cases (factor $k=0.64$ ), and for $150 \mu \mathrm{m}$ corrosion penetration according to section 2.3 above. 


\subsection{Beam tests by Rodriguez et al.}

One of the beams tested by Rodriguez et al. (1997), see brief description in section 3.2 above, was modeled and analyzed by the finite element method (FEM). Both the tests with uncorroded and corroded reinforcement were analyzed. The effect of reinforcement corrosion was modeled as a change of rebar diameter and by modification of bond-slip properties according to sections 2.2 and 2.3 above.

The beam was modeled in 2D, and due to symmetry; only half of the beam was modeled. The dimensions, reinforcement, boundary conditions and loading arrangement are shown in Figure 6 . The steel plates and roller bearings at the supports and loading points were modeled by rigid constraints in the same manner as described in section 4.1 above. At the symmetry line, see the right end of the beam in the figure, all the nodes were fixed in the x-direction.

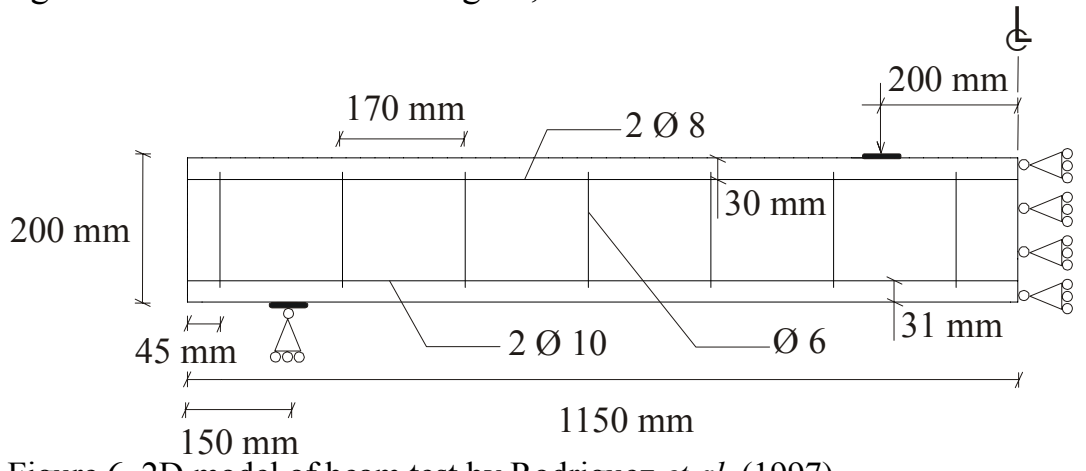

Figure 6. 2D model of beam test by Rodriguez et al. (1997)

The concrete was modeled by 4-node quadrilateral plane stress solid elements with the same type of material laws as described in section 4.1 above, using concrete material data according to Table 2.

Table 2. Material properties used in the analyses

\begin{tabular}{llllllll}
\hline \multirow{3}{*}{ Material Properties } & \multicolumn{2}{l}{ Concrete } & & & & \multicolumn{2}{c}{ Reinforcement } \\
\cline { 2 - 4 } \cline { 7 - 8 } & $\mathrm{f}_{\mathrm{cc}}$ & $\mathrm{f}_{\mathrm{ct}}$ & $\mathrm{G}_{\mathrm{F}}$ & $\mathrm{E}_{\mathrm{c}}$ & & $\mathrm{f}_{\mathrm{y}}$ & $\mathrm{E}_{\mathrm{c}}$ \\
& {$[\mathrm{MPa}]$} & {$[\mathrm{MPa}]$} & {$[\mathrm{N} / \mathrm{m}]$} & {$[\mathrm{GPa}]$} & & {$[\mathrm{MPa}]$} & {$[\mathrm{GPa}]$} \\
Uncorroded & 49.9 & 3.62 & 92.4 & 34.97 & & 575 & 200 \\
Corroded & 36.8 & 2.82 & 74.7 & 31.6 & & 575 & 200 \\
\hline
\end{tabular}

The reinforcement and the interaction between the reinforcement and concrete as well as the effect of corrosion were modeled in the same way as described in section 2. Figure 7 shows the resulting bond-slip curves for 0 and $490 \mu \mathrm{m}$ corrosion penetration. An incremental static analysis was performed in the same manner as described in section 4.1 above.
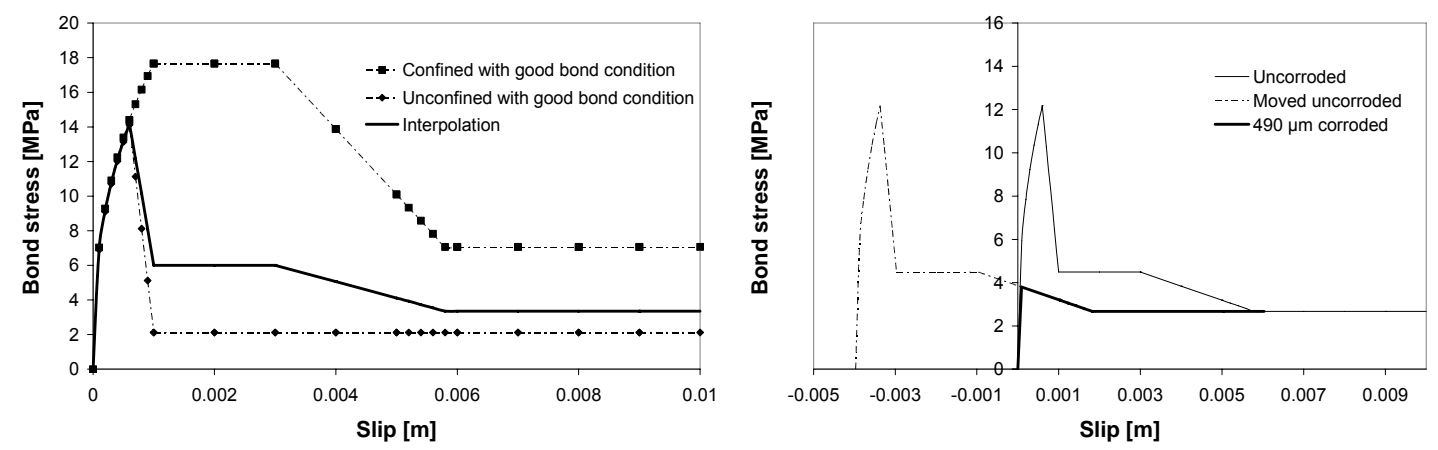

Figure 7. Bond-slip curve for uncorroded reinforcement obtained by interpolation of "confined" and "unconfined" cases (factor $k=0.25$ ), and for $490 \mu \mathrm{m}$ corrosion penetration according to section 2.3 above 


\section{RESULTS}

\subsection{Beam test by Coronelli}

Figure 8 shows comparisons between computed and measured results for the Coronelli beams with $0,50,100$ and $150 \mu \mathrm{m}$ corrosion penetrations. All beams failed due to pull-out failure, which agrees well with the experimental observations. The initial stiffness for the beams agrees very well for all cases. Also the maximum load agrees fairly well for all cases, but differences are visible in the post-peak behavior. Noticeable is also that the maximum load only goes down from $75 \mathrm{kN}$ for the uncorroded case to $65 \mathrm{kN}$ for the case with $150 \mu \mathrm{m}$ corrosion penetration. Probably it would have been more interesting to test beams with higher amounts of corrosion.
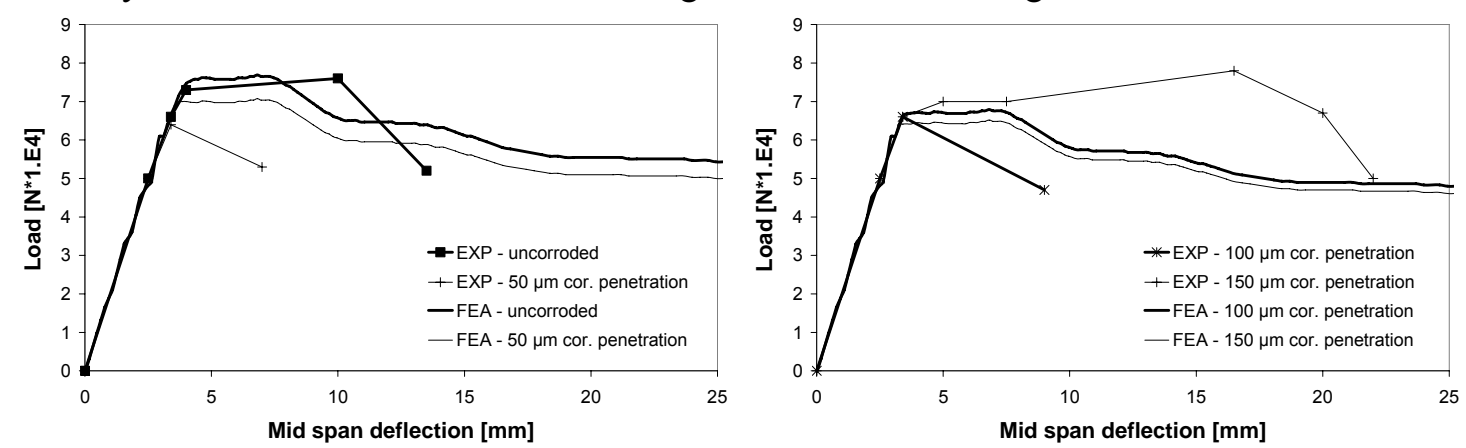

Figure 8. Comparison between computed and measured load-displacement curves for uncorroded and 50, 100 and $150 \mu \mathrm{m}$ corrosion penetrations for Coronelli beams

\subsection{Beam test by Rodriguez et al.}

Figure 9 shows comparisons between computed and measured results for the Rodriguez beams with 0 and $490 \mu \mathrm{m}$ corrosion penetrations.

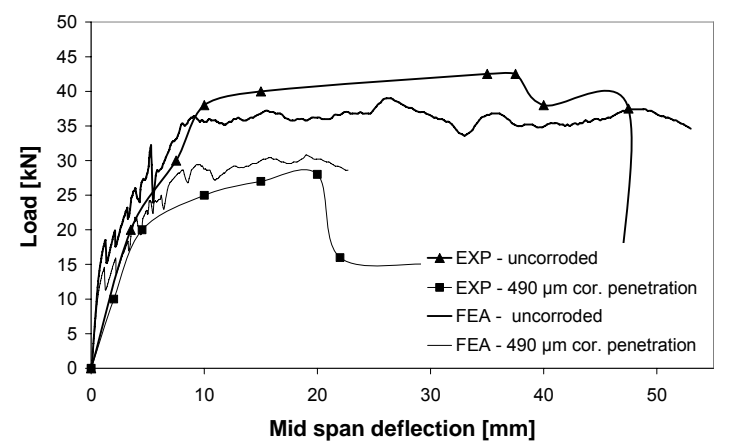

Figure 9. Comparison between computed and measured load-displacement curves for Rodriguez beams.

Both beams failed due to yielding of reinforcement, which agrees well with the experimental observations. The initial stiffness for the beams agrees well. Also the maximum load agrees fairly well.

\section{CONCLUSIONS}

The paper has presented a methodology to analyze the mechanical behavior of corrosiondamaged reinforced concrete structures. It is proposed that the mechanical effects of corrosion can be modeled as change in geometry and properties, i.e. reduction of steel area, removal of spalled concrete and modification of bond-slip properties.

The methodology was used in combination with non-linear fracture mechanics in finite element analysis using the program DIANA. The results of the analyses were compared with available experimental results to verify the capability of the proposed method to predict the load- 
carrying capacity of the corroded structural members. Based on the results of the analyses, the following conclusions can be drawn:

1. The experimental setups for the Coronelli beams had too low corrosion penetrations $(\leq 150 \mu \mathrm{m})$ to give significant effect on the load-carrying capacity of the member.

2. For the Coronelli beams, the agreement between the analysis results and the experiments for the presented cases is reasonable in terms of load-carrying capacity, i.e. maximum load, but differences occurred in the post-peak behavior.

3. For the Rodriguez beams, the agreement between the analysis results and the experiments is reasonable.

Based on these conclusions, and the intention with the proposed methodology, future work should concentrate on the following issues:

1. Application of the model to a larger range of experiments with beams with heavily corroded reinforcement especially beams with curtailed and/or lapped reinforcement that fail due to bond failure.

2. Settle model parameters with respect to predictive capability and safety aspects for application in engineering practice for assessment of load-carrying capacity of corrosiondamaged reinforced concrete structures.

\section{REFERENCES}

Almusallam, A. A., Al-Gahtani, A. S. and Aziz, A. R. 1996. Effect of reinforcement corrosion on bond strength. Construction and Building Materials, Vol. 10, No. 2, Mar, pp. 123129.

CEB 1993 CEB-FIP Model Code 1990. Lausanne, Switzerland: Bulletin d'Information 213/214

Coronelli, D. 1998. Bar corrosion in steel-concrete bond: material and structural effects in $R / C$. $\mathrm{Ph}$. D. Thesis, Structural Engineering Department, Politecnico di Milano, Milano, 1998, $201 \mathrm{pp}$.

fib 2000 Bond of reinforcement in concrete, State-of-art report. fib bulletin 10, Fédération internationale du béton, prepared by Task Group Bond Models, Lausanne.

Huang, R. and Yang, C. C. 1997. Condition assessment of reinforced concrete beams relative to reinforcement corrosion. Cement and Concrete Composites, Vol. 19, No. 2, pp. 131.

Lundgren, K. Year Modelling the splitting effects of corrosion in reinforced concrete. Computational Modelling of Concrete Structures, Euro-C Conference, St. Johann, Austria, 2003, 491-500.

Lundgren, K. 2004. Bond between ribbed bars and concrete: Part 2. The effect of corrosion. Accepted for publication in Magazine of Concrete Research.

Lundgren, K., Kettil, P., Hanjari, K. Z., Schlune, H. and Roman, A. S. S. in progress. Analytical model for the bond-slip behaviour of corroded reinforcement.

Lundgren, K., Roman, A. S. S., Schlune, H., Hanjari, K. Z. and Kettil, P. Year Effects on bond of reinforcement corrosion. International RILEM workshop on Integral Service Life Modeling of Concrete Structures, 5-6 November 2007, Guimaraes, Portugal, 2007, 231238.

Meria, G. R., Andrade, C., Alonso, C. and Jr., J. C. B. Year Chloride penetration into concrete structures in marine atmosphere zone - influence of environmental characteristics. International RILEM workshop on Integral Service Life Modeling of Concrete Structures, 5-6 November 2007, Guimaraes, Portugal, 2007.

Rodriguez, J., Ortega, L. M. and Casal, J. 1997. Load carrying capacity of concrete structures with corroded reinforcement. Construction and Building Materials, Vol. 11, No. 4, Jun, pp. 239-248.

Schlune, H. 2006 Bond of corroded reinforcement: analytical description of the bond-slip response. Göteborg: Chalmers tekniska högskola 